\title{
ADENO-ASSOCIATED VIRAL VECTOR TRANSDUCTION OF HUMAN MESENCHYMAL STEM CELLS
}

\author{
Stefan Stender ${ }^{1,2}$, Mary Murphy' ${ }^{1}$, Tim O’Brien ${ }^{1}$, Carsten Stengaard ${ }^{2}$, Michael Ulrich-Vinther ${ }^{2}$, \\ Kjeld Søballe², Frank Barry ${ }^{1}$
}

${ }^{1}$ Regenerative Medicine Institute, National University of Ireland, Galway, Ireland

${ }^{2}$ Department of Orthopaedics, Aarhus University Hospital, Aarhus, Denmark

\begin{abstract}
Mesenchymal stem cells (MSCs) have received considerable attention in the emerging field of regenerative medicine. One aspect of MSC research focuses on genetically modifying the cells with the aim of enhancing their regenerative potential. Adeno-associated virus (AAV) holds promise as a vector for human gene therapy, primarily due to its lack of pathogenicity and low risk of insertional mutagenesis. However, the existing data pertaining to AAV transduction of MSCs is limited.

The objective of this work was to examine the efficiency and kinetics of in vitro transduction using AAV serotype 2 in human MSCs and to assess whether AAV transduction affects MSC multipotentiality. The results indicated that human MSCs could indeed be transiently transduced in vitro by the AAV2 vector with efficiencies of up to $65 \%$. The percentage of GFP-positive cells peaked at 4 days posttransduction and declined rapidly towards $0 \%$ after day 8 . The level of transgene expression in the GFP-positive population increased 4-fold over a 10,000 fold viral dose increase. This dose-response contrasted with the 200 -fold increase observed in similarly transduced 293-cells, indicating a relatively restricted transgene expression in MSCs following AAV mediated gene delivery. Importantly, transduced MSCs retained multipotential activity comparable to untransduced controls.
\end{abstract}

Key Words: Mesenchymal stem cells, adeno-associated virus, transgene expression, multipotential activity.

\footnotetext{
*Address for correspondence:

Frank Barry

Regenerative Medicine Institute

National University of Ireland

Galway, Ireland.

Telephone Number: +353-91-4951208

E-mail: frank.barry@nuigalway.ie
}

\section{Introduction}

Adult mesenchymal stem cells (MSCs) have received considerable attention in the emerging field of regenerative medicine (Barry and Murphy, 2004). MSCs can differentiate into a variety of mesenchymal lineages, including chondrocytes, osteocytes, adipocytes, tenocytes and myocytes (Wakitani et al., 1995; Awad et al., 1999; Pittenger et al., 1999). This multipotentiality combined with their ease of isolation and high capacity for in vitro expansion has attracted considerable interest in their use in tissue engineering applications.

A remarkable feature of MSCs is their apparent ability to migrate towards and engraft at sites of injury in vivo. Following engraftment, they elicit a regenerative effect on the injured tissue. This activity underpins the strong interest in the therapeutic use of MSCs in diseases such as myocardial infarction (Oulic et al., 2001; Woller et al., 2004), neuronal injury (Wang et al., 2002) and osteoarthritis (Murphy et al., 2003; Wakitani et al., 2003).

However, there are several questions concerning the use of MSCs that need to be addressed. Firstly, both in vitro and in vivo studies show that differentiated MSCs can transdifferentiate or dedifferentiate (Muraglia et al., 2003; De Bari et al., 2004) and a method of securing their phenotypic stability following differentiation will be useful. Secondly, although intravenously injected MSCs engraft in damaged tissues, a majority lodge in the vasculature of the lung and other highly vascularized organs (Gao et al., 2001). A method of achieving tissuespecific homing and engraftment of MSCs would be a major step towards a potent and cost-efficient therapy.

We and others have looked at gene therapy to overcome the above mentioned limitations. In a tissue engineering context MSCs can be genetically modified to express transcription factors or growth factors that induce differentiation along a desired lineage (Carlberg et al., 2001; Gels et al., 2001; Katayama et al., 2004). Tissue-specific homing and engraftment of MSCs could be achieved by the introduction of genes for tissue-specific cell surface adhesion molecules. Furthermore, as MSCs engraft in damaged tissues, genetically engineered MSCs could be employed as a means of delivering therapeutically active proteins to these tissues (Stagg et al., 2004; Reiser et al., 2005; Kim et al., 2006; Goncalvos et al., 2006).

Most efforts have relied on adeno- and lentiviral vectors for delivering genes to MSCs. Effective as these vectors may be, concerns regarding their immunogenicity and, in the case of lentivirus, the risk of insertional mutagenesis, have led to the pursuit of safer alternatives. 
Among these, adeno-associated virus (AAV), a small parvovirus, holds several advantages as a vector for human gene therapy, the most obvious being its lack of pathogenicity. For a recent review of past and ongoing clinical trials with AAV, see Carter (2005).

The few published studies that utilize AAV transduction of MSCs agree on the feasibility of this (Ho et al., 2004; Kumar et al., 2004; Kumar et al., 2005; Bosch et al., 2006; McMahon et al., 2006). However, these studies leave several basic questions regarding transduction efficiency and kinetics unanswered. In the present study, flow cytometry and fluorescence microscopy were used to examine the in vitro transduction efficiency of AAV serotype 2 in human MSCs. Furthermore, we evaluated whether transduction with AAV altered the differentiation potential of the cells.

\section{Materials and Methods}

\section{Isolation of human MSCs}

MSCs were isolated by direct technique as described previously (Murphy et al., 2006). In brief, heparinized bone marrow aspirates $(10 \mathrm{~mL})$ were taken from the iliac crest of healthy donors. Marrow was obtained after informed consent and all procedures were approved by the Clinical Research Ethical Committee at University College Hospital, Galway. Marrow was diluted 10-fold in phosphate-buffered saline (PBS). The cell fraction was separated by centrifugation and seeded on T-175 flasks in DMEM-LG containing $1 \mathrm{~g} / \mathrm{L}$ glucose with $10 \%$ FBS (Gibco, Invitrogen, Dun Laoghaire, Ireland)) of a batch previously determined to support MSC growth at 300,000 cells $/ \mathrm{cm}^{2}$ for culture at $37^{\circ} \mathrm{C}$ with $95 \%$ humidity and $5 \%$ $\mathrm{CO}_{2}$ in the same medium. After 5 days red blood cells were washed off with PBS and fresh medium was added. Colonies of adherent cells formed within 9 days. The colonies were trypsinized from the flasks when they covered $60 \%$ to $90 \%$ of the plate and were cryopreserved for later use. Upon thawing, MSCs were expanded through several passages prior to viral transduction. All MSCs used in this study were from passage 5. Flow cytometry (FACSCalibur, Beckton Dickinson (BD), Oxford, UK) demonstrated that the cells were homogenously CD105+, CD34-, CD45-, CD14-, which is a typical MSC surface antigen profile (Tuli et al., 2003) (data not presented).

\section{Preparation of rAAV-eGFP vector}

The enhanced green fluorescent protein (eGFP) gene under transcriptional control of a TRUFR promoter was cloned into the rAAV vector backbone. The rAAV-eGFP virus was prepared using the adenovirus-free system by the Gene Core Facility, University of North Carolina at Chapel Hill, $\mathrm{NC}$, USA. The concentration of infectious rAAV-eGFP particles was approximately $4.5 \times 10^{10}$ per $\mathrm{mL}$ determined by titration on human embryonic kidney cells.

\section{Transduction of hMSCs or 293-cells}

MSCs were plated in 24-wells at 10,000 cells/well and $500 \mu \mathrm{l}$ MSC medium was added per well. Cells were allowed to attach for $24 \mathrm{~h}$ before virus was added directly to the medium at 1,10,100,1,000 and 10,000 multiplicities of infection (MOI). Media were changed after $24 \mathrm{~h}$ and every $48 \mathrm{~h}$ for the remaining culture period. The procedure for transducing 293-cells (human embryonic kidney cells) was identical, except that 20,000 cells were seeded per well.

Harvest of MSCs and preparation for flow cytometry Cultures were trypsinized and collected in separate Eppendorf tubes. Cells were stained with 7-AAD (Guava Technologies, Hayward, CA, USA; cell viability kit) after which they were left in the dark for 20 minutes at $4{ }^{\circ} \mathrm{C}$ to allow for staining of dead cells. The cells were resuspended in BD Cellwash (BD Biosciences) and analysed for eGFP expression and 7-AAD staining on a GUAVA Easycyte R, (Guava Technologies). 5,000 cells were counted per acquisition. The percentage of viable cells expressing eGFP and the mean fluorescence intensity (MFI) in this population was assayed.

\section{Osteogenesis}

20,000 AAV-eGFP (MOI 100) transduced or untransduced MSCs/well were seeded in a 6-well plate, $\mathrm{N}=3.2 \mathrm{~mL}$ MSC medium was added per well. After $24 \mathrm{~h}$, medium was removed and $2 \mathrm{~mL}$ osteoinductive medium (MSC medium, $100 \mathrm{nM}$ Dexamethasone, $10 \mathrm{mM}$ Beta-Glycerophosphate, $50 \mu \mathrm{M}$ Ascorbic acid 2-phosphate added. Unless otherwise noted, all reagents were acquired from Sigma Aldrich (Dublin, Ireland). Medium was changed every 3-4 days. Cultures were harvested at day 18. Calcium deposition was evaluated quantitatively with a StanBio Calcium Liquicolour Kit (Stanbio, Boerne, TX, USA) and qualitatively by Von-Kossa staining of formalin fixed cultures. Cultures grown in MSC medium for the entire period served as negative controls, $\mathrm{N}=3$.

\section{Adipogenesis}

200,000 AAV-eGFP (MOI 100) transduced or untransduced MSCs/well were seeded in a 6-well plate, $\mathrm{N}=3$. Cells were cultured to confluence in MSC medium (4 days). The cultures were subjected to 3 cycles of $72 \mathrm{~h}$ in adipogenic induction medium (DMEM-HG (4, 5 gm glucose/L), 10\% FBS, $1 \mu \mathrm{M}$ dexamethasone, $500 \mu \mathrm{M}$ methyl-isobutylxanthine, and $10 \mu \mathrm{g} / \mathrm{ml}$ insulin), followed by 24 hours in maintenance medium (DMEM-HG, 10\% FBS, and $10 \mu \mathrm{g} / \mathrm{ml}$ insulin). After cycle 3, cells were grown an additional week in maintenance medium, after which they were fixed with $10 \%$ formalin and stained with Oil Red O for detection of lipid vacuoles. MSCs grown in MSC medium served as negative controls, $\mathrm{N}=3$.

\section{Chondrogenesis}

MSCs in monolayer were transduced with AAV2-eGFP at MOI 100, $\mathrm{N}=5$. Untransduced cells served as controls, $\mathrm{N}=5.24 \mathrm{~h}$ post transduction, the cells were trypsinized, spun at $100 \mathrm{x} \mathrm{g}$ for $5 \mathrm{~min}$ and resuspended in complete chondrogenic medium (CCM) (Dulbecco's Modified Eagle's Medium (DMEM) high glucose, $10 \mathrm{ng} / \mathrm{mL}$ TGF$\beta 3,6.25 \mu \mathrm{g} / \mathrm{mL}$ insulin, $6.25 \mu \mathrm{g} / \mathrm{mL}$ transferrin, $6.25 \mu \mathrm{g}$ / 
$\mathrm{mL}$ selenous acid, $5.33 \mu \mathrm{g} / \mathrm{mL}$ linoleic acid, $1.25 \mu \mathrm{g} / \mathrm{mL}$ bovine serum albumin (BSA), $100 \mathrm{nM}$ dexamethasone, $50 \mu \mathrm{g} / \mathrm{mL}$ Ascorbic acid-2-phosphate, $40 \mu \mathrm{g} / \mathrm{mL}$ proline, $1 \mathrm{mM}$ sodium pyruvate, antibiotic/antimycotic). $2 \times 10 \mathrm{e} 5$ cells/tube were transferred to $15 \mathrm{~mL}$ polypropylene tubes. Tubes were spun at $100 \mathrm{x}$ g for $5 \mathrm{~min}$. Medium was aspirated and the pellets were subsequently cultured in CCM which was changed every 2-3 days. Cells resuspended and cultured in incomplete chondrogenic medium (CCM minus TGF- $\beta 3$ ) served as negative controls. Glycosaminoglycan (GAG) content was quantified after 21 days of culture using the DMMB assay as previously described (Murphy et al., 2002). DNA content was measured by the DNA Quant-It Kit (Molecular Probes, Eugene, OR, USA).

\section{Microscopy}

Microscopic images of eGFP-positive cells were acquired using an Olympus (Hamburg, Germany) IX71 inverted fluorescent microscope.

\section{Statistics}

Transduction efficiencies and MFIs were directly acquired from the GUAVA Easycyte software after gating for dead cells and autofluorescence. 5 samples were acquired for each time point and MOI. Means and standard error of the mean (SEM) are depicted in bar graphs. Statistical analysis was carried out using Student's t-test as data could be approximated to normal distribution.

\section{Results}

Transduction efficiencies ranged from $1 \%$ for MOI 1 to $65 \%$ for MOI 10,000 (Fig. 1). A peak in percentage of GFP-positive cells was observed at 4 days post transduction for $\mathrm{MOI} \geq 100$. Long term expression of MOI 1000 transduced cultures was assayed at day 8 to 32 post transduction. A dramatic time related reduction in percentage of GFP-positive cells was observed with 2\% green cells between day 16 and 24, and a further decrease to $\sim 0.5 \%$ at day 32 (data not shown). The decline of GFPpositive MSCs over time can be explained by the replication deficiency of the AAV vector and by the fact that AAV does not integrate in the host cellular chromosome which prohibits vertical vector transmission in dividing cell cultures. Viability assayed by trypan blue

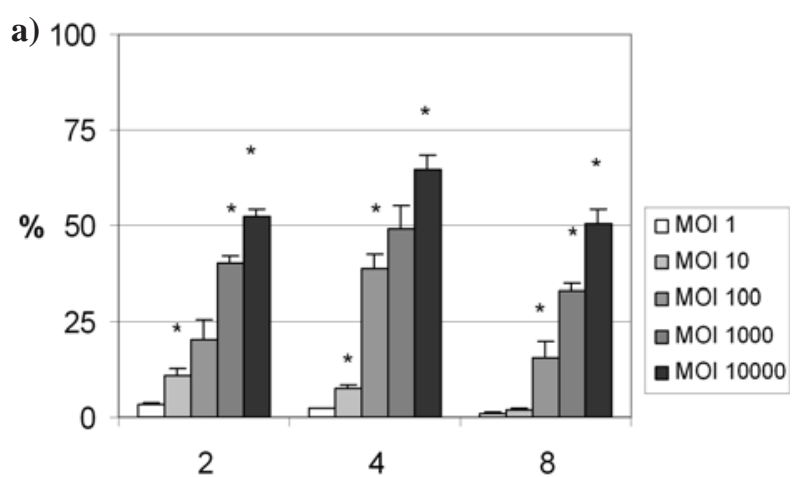

Days post transduction

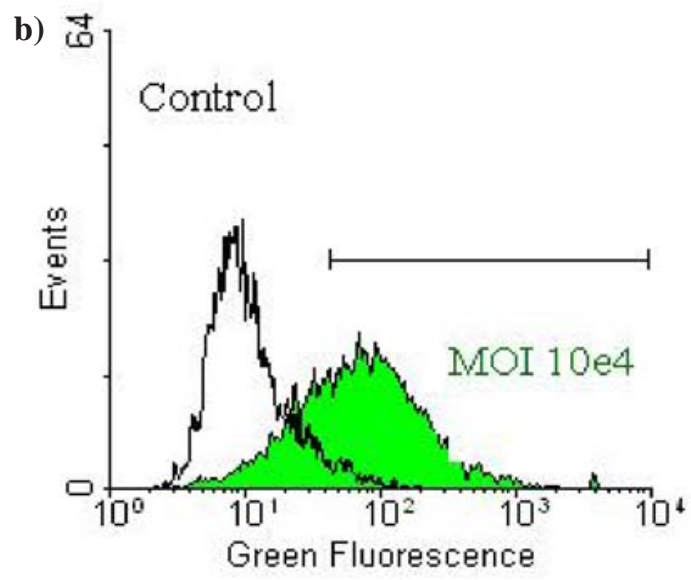

Figure 1. a) Mean + sem transduction efficiency of AAV2 in hMSCs. Each bar is based on flow cytometry of 5 samples. * represent $p<0.05$ compared to 10 -fold lower MOI dose at the same time point. b) Representative histogram of MOI 10,000 transduced MSCs vs control, 4 days post transduction. Bar indicates $65 \%$ of transduced cells, $5 \%$ of untransduced cells (autofluorescence).

exclusion or 7-AAD staining was high $(>95 \%)$ in all samples studied (data not shown).

\section{Microscopy}

Intensity of fluorescence in transduced MSCs was low with MOI 1-100 transduced cultures virtually indistinguishable from controls. In contrast, numerous bright fluorescent cells were visible in MOI 1,000 and 10,000 transduced cultures (Fig. 2). This fluorescence was completely absent in uninfected controls.
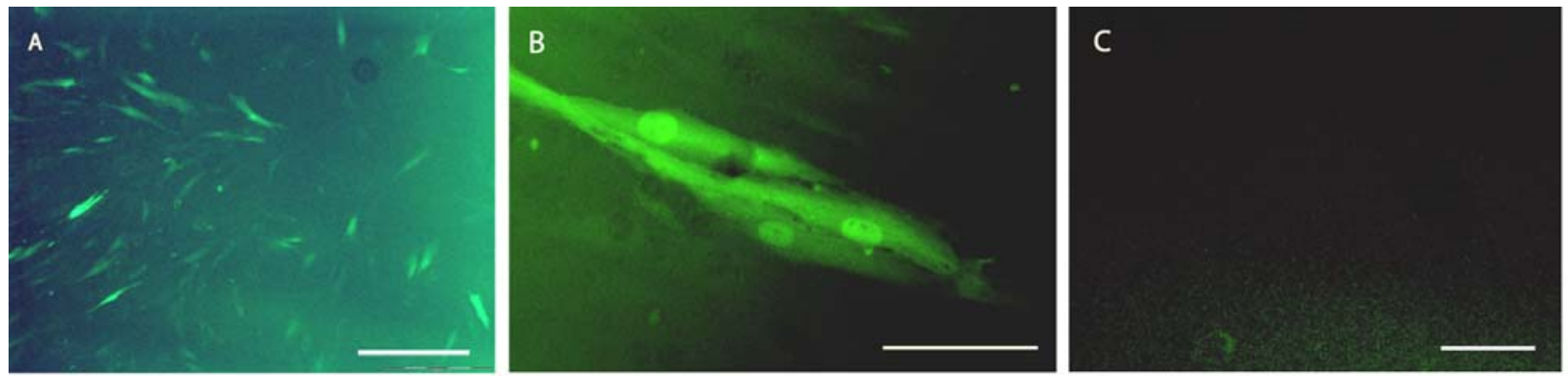

Figure 2. GFP expression at day 4 post transduction in MOI 10,000 transduced MSCs $(\mathrm{A}+\mathrm{B})$ and untransduced controls (C). 


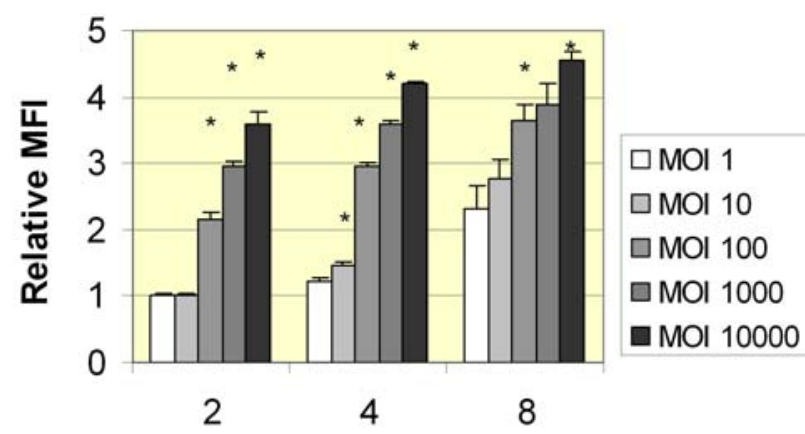

Days post transduction

Figure 3. Relative MFIs + sem of GFP-positive AAVGFP transduced MSCs. * indicate $p<0.05$ compared to a 10-fold lower MOI dose at the same time point.

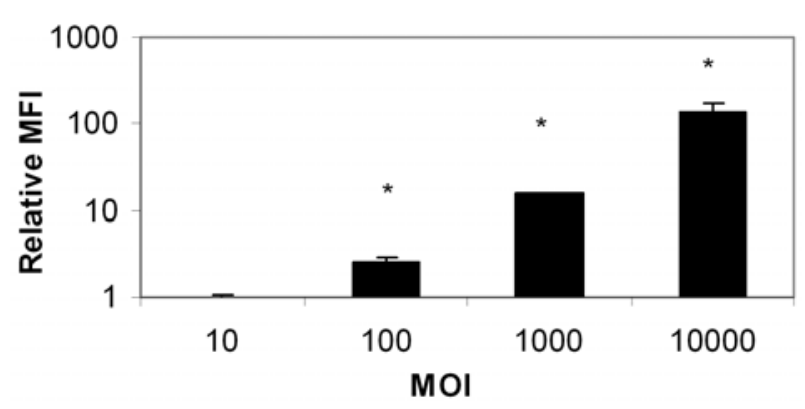

Figure 4. Relative MFIs + sem of AAV-GFP transduced 293-cells, day 4 post transduction. * indicate $p<0.05$ compared to a 10 -fold lower MOI dose.

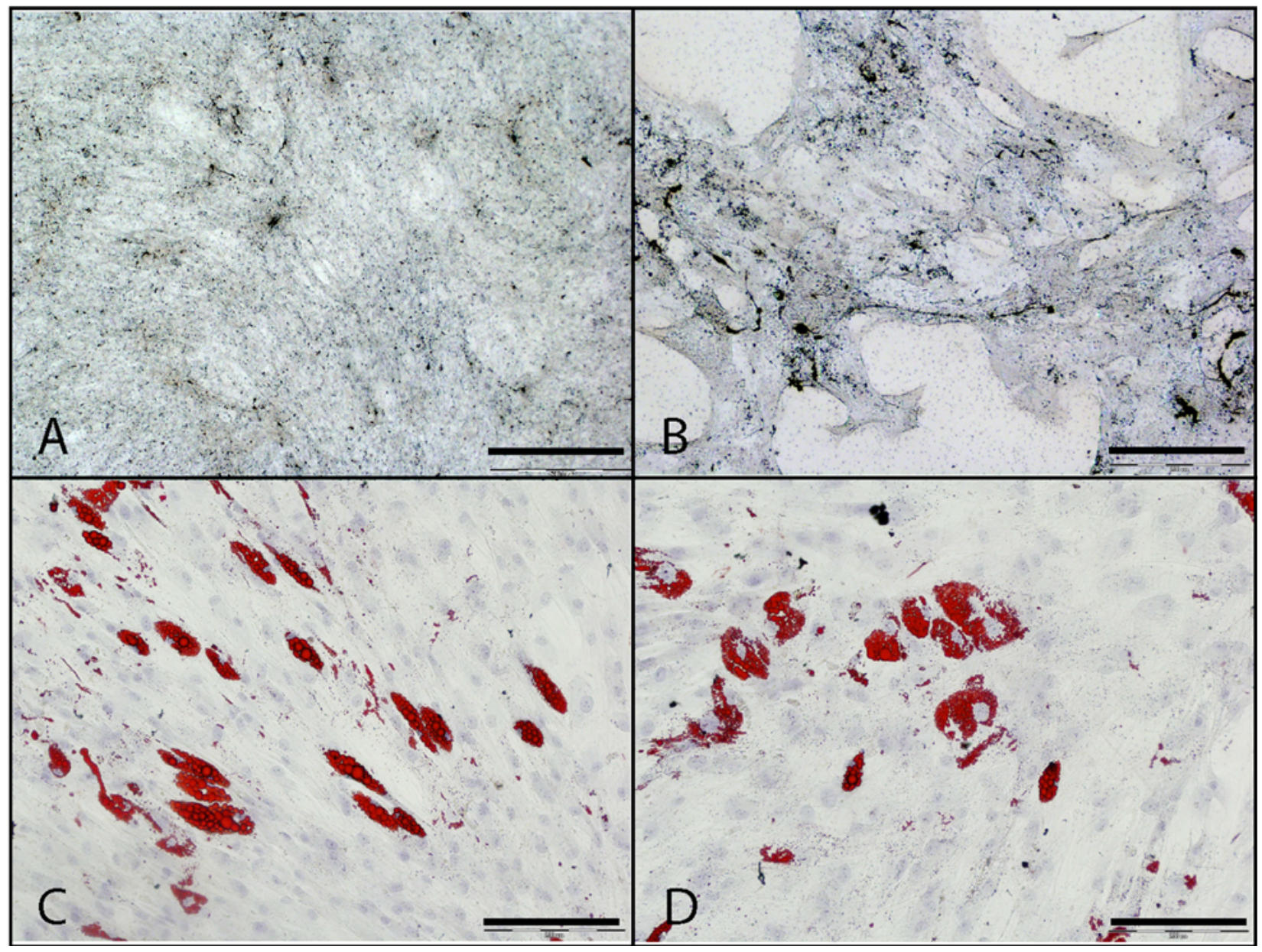

Figure 5. Von Kossa staining of untransduced (A) and AAV-GFP transduced (MOI 100) (B) osteogenic differentiated MSCs, bar $=500 \mu \mathrm{m}$. Adipogenesis of untransduced (C) and AAV-GFP transduced (MOI 100) MSCs (D), bar $=200$ $\mu \mathrm{m}$.

\section{Mean fluorescence intensity (MFI)}

Mean fluorescence intensity (MFI) is a parameter for the cellular synthesis of transgene GFP in the AAV-GFP transduced cell population. In order to evaluate the level of transgene expression, cells positive for GFP were analyzed for MFI (Fig. 3).

A 10,000 fold increase in viral dose gave a $\sim 4$ fold increase in MFI of GFP-positive MSCs at day 4 post transduction. We compared this result to the results from a similar transduction experiment conducted on 293-cells, a cell-line known to be permissive for AAV transduction.
MFIs of GFP-positive 293-cells increased 200 fold over the same range of viral doses that only produced a $\sim 4$-fold MFI increase in MSCs (Fig. 4). Thus, although it is possible to achieve high transduction efficiencies with AAV in hMSCs, the level of transgene expression in the transduced population appears to be severely restricted, at least compared to 293-cells.

\section{Differentiation assays}

Importantly, AAV-GFP transduced hMSCs retained multipotential activity comparable to untransduced cells. 


\section{Osteogenesis}

AAV-GFP transduced (MOI 100) MSCs retained the ability to differentiate along the osteogenic lineage as determined by Van Kossa staining of deposited calcium (Fig. 5A+B). There was no difference in the amount of deposited calcium between transduced and untransduced cultures, $\mathrm{N}=2$ (Fig. $6)$.

\section{Adipogenesis}

AAV-GFP transduced (MOI 100) MSCs underwent adipogenesis with the same efficiency as untransduced cells, indicated by the production of lipid vacuoles after 21 days of culture in adipogenic medium (Fig. $5 \mathrm{C}+\mathrm{D}$ ).

\section{Chondrogenesis}

AAV-GFP transduced (MOI 100) MSCs produced glycosaminoglycans (GAG) at comparable levels to untransduced cells, $\mathrm{N}=5$ (Fig. 7).

\section{Discussion}

We found that high doses of AAV2 could transduce MSCs in vitro with efficiencies of up to $65 \%$. In order to assess the level of transgene expression in the transduced population, we compared MFIs of transduced hMSCs to similarly transduced 293-cells. Whereas MFIs of GFPpositive 293-cells increased 200 fold upon increasing the viral dose 10,000 fold, MFIs in similarly transduced MSCs only increased $\sim 4$ fold. This indicates that although AAV2 can transduce MSCs, levels of transgene expression remain severely restricted. Consistent to our results, Ito et al. reported a tiny increase (approximately $+5 \%$ compared to untransduced cells) in extracellular TGF $\beta 1$ concentrations following AAV mediated delivery of this gene to MSCs (Ho et al., 2004). These results and our own failure to induce chondrogenic differentiation in MSCs by transduction with the same AAV-TGF $\beta 1$ vector (data not presented here) lead us to suggest that in MSCs, AAV is better suited to introduce genes for proteins that exert their function at lower concentrations. Transcription factors or cellular adhesion molecules are obvious candidates.

There may be several reasons for the low transgene expression following AAV mediated gene delivery to MSCs. A scarcity of the primary cell surface receptor for AAV, heparin sulfate proteoglycan (Summerford and Samulski, 1998), on the cellular surface of MSCs might limit the number of endocytosed virions. Uncoating of virions following cellular uptake was recently described as an important barrier to efficient AAV transduction (Hauck et al., 2004). Second strand synthesis following virion uncoating and nuclear delivery of the single stranded viral genome is another rate limiting step for AAV transduction (Ferrari et al., 1996; Fischer et al., 1996). Presumably, a yet-to-be-identified cellular DNA repair mechanism is responsible for this second strand synthesis. It is interesting to note that the DNA repair in undifferentiated stem cells is less error-prone than in more differentiated cells (Bill et al., 1991; Saretzki et al., 2004). Hypothetically, cells that exert a more stringent control over their DNA-repair enzymes will be less likely to

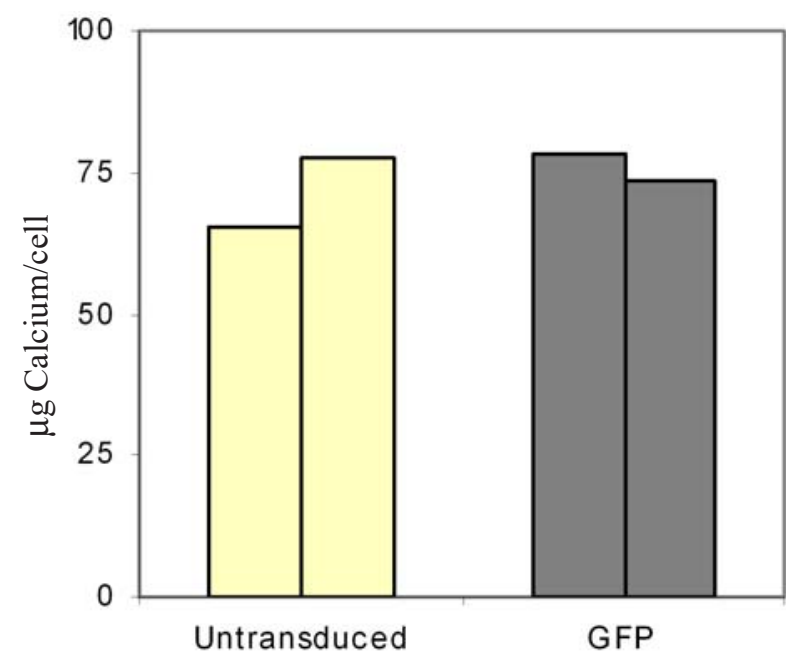

Figure 6. Calcium deposition in untransduced versus AAV-GFP transduced osteogenic differentiated MSCs, $\mathrm{N}=2$.

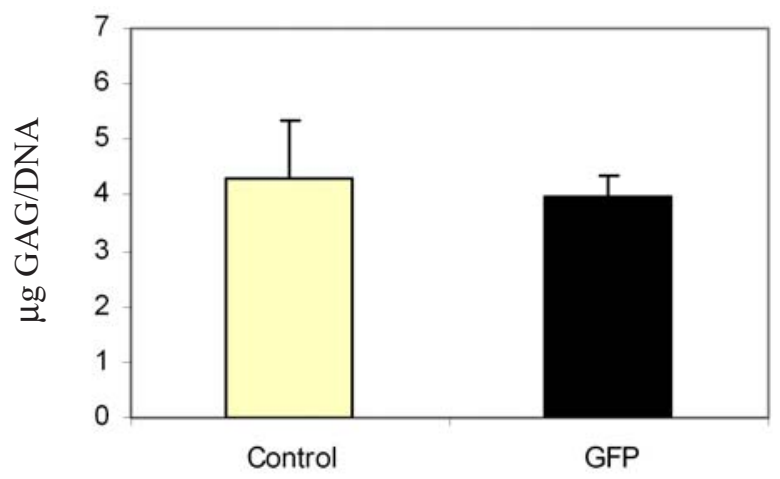

Figure 7. Production of GAG + sem in control and MOI 100 transduced MSCs, $\mathrm{N}=5$. There was no statistical difference in levels of GAG between the two groups ( $p$ $=0.893)$.

mistake single stranded viral DNA for damaged genomic DNA in need of repair. Thus, a highly stringent DNArepair mechanism in MSCs could play a role in the low transgene expression observed in this study.

The duration of transgene expression is a clinically highly relevant parameter. We observed a peak of GFPpositive cells at 4 days post transduction followed by a rapid decline to near control levels after day 16. It is worth noting that many MSC-based therapies currently under investigation aim at healing, which is ideally a transient process. With this in mind, AAV-mediated gene therapy of MSCs could be utilized as a way of temporarily supplying the MSCs with beneficial genes while the healing is ongoing without risking potential adverse effects of long term transgene expression. Finally, it is important to note that the transient expression observed in vitro in this study might not correlate to the in vivo situation. For instance, the duration of transgene expression for haematopoietic stem cells transduced with AAV was much longer in vivo than in vitro (Ponnazhagan et al., 1997), presumably due to more frequent cellular divisions in vitro.

In conclusion, high titers of AAV2-GFP transiently transduce human MSCs in vitro with efficiencies of up to $65 \%$. A low level of transgene expression is a drawback 
that needs to be taken into consideration for future studies utilizing AAV-mediated gene delivery to MSCs. Importantly, AAV2-GFP transduced MSCs retained multipotential activity comparable to untransduced cells.

\section{Acknowledgements}

SS was supported by grant no 22-04-0152 from the Danish state, MM and FB were supported by Science Foundation Ireland. We wish to thank T. Bowes, REMEDI for help with flow cytometry and R.J. Samulski, Gene Core Facility, University of North Carolina for production of AAV-vector.

\section{References}

Awad HA, Butler DL, Boivin GP, Smith FN, Malaviya P, Huibregtse B, Caplan AI (1999) Autologous mesenchymal stem cell-mediated repair of tendon. Tissue Eng 5: 267-277.

Barry FP, Murphy JM (2004) Mesenchymal stem cells: clinical applications and biological characterization. Int J Biochem Cell Biol 36: 568-584.

Bill CA, Grochan BM, Meyn RE, Bohr VA, Tofilon PJ (1991) Loss of intragenomic DNA repair heterogeneity with cellular differentiation. J Biol Chem 266: 2182121826.

Bosch P, Pratt SL, Stice SL (2006) Isolation, characterization, gene modification, and nuclear reprogramming of porcine mesenchymal stem cells. Biol Reprod 74: 46-57.

Carlberg AL, Pucci B, Rallapalli R, Tuan RS, Hall DJ (2001) Efficient chondrogenic differentiation of mesenchymal cells in micromass culture by retroviral gene transfer of BMP-2. Differentiation 67: 128-138.

Carter BJ (2005) Adeno-associated virus vectors in clinical trials. Hum Gene Ther 16: 541-550.

De Bari C, Dell'Accio F, Luyten FP (2004) Failure of in vitro-differentiated mesenchymal stem cells from the synovial membrane to form ectopic stable cartilage in vivo. Arthritis Rheum 50: 142-150.

Ferrari FK, Samulski T, Shenk T, Samulski RJ (1996) Second-strand synthesis is a rate-limiting step for efficient transduction by recombinant adeno-associated virus vectors. J Virol 70: 3227-3234.

Fisher KJ, Gao GP, Weitzman MD, DeMatteo R, Burda JF, Wilson JM (1996) Transduction with recombinant adeno-associated virus for gene therapy is limited by leading-strand synthesis. J Virol 70: 520-532.

Gao J, Dennis JE, Muzic RF, Lundberg M, Caplan AI (2001) The dynamic in vivo distribution of bone marrowderived mesenchymal stem cells after infusion. Cells Tissues Organs 169: 12-20.

Gelse K, von der MK, Aigner T, Park J, Schneider H (2003) Articular cartilage repair by gene therapy using growth factor-producing mesenchymal cells. Arthritis Rheum 48: 430-441.

Goncalves MA, de Vries AA, Holkers M, van de Watering MJ, van de Velde I, van Nierop GP, Valerio D,
Knaan-Shanzer S (2006) Human mesenchymal stem cells ectopically expressing full-length dystrophin can complement Duchenne muscular dystrophy myotubes by cell fusion. Hum Mol Genet 15: 213-221.

Hauck B, Zhao W, High K, Xiao W (2004) Intracellular viral processing, not single-stranded DNA accumulation, is crucial for recombinant adeno-associated virus transduction. J Virol 78: 13678-13686.

Ito H, Goater JJ, Tiyapatanaputi P, Rubery PT, O'Keefe RJ, Schwarz EM (2004) Light-activated gene transduction of recombinant adeno-associated virus in human mesenchymal stem cells. Gene Ther 11: 34-41.

Katayama R, Wakitani S, Tsumaki N, Morita Y, Matsushita I, Gejo R, Kimura T (2004) Repair of articular cartilage defects in rabbits using CDMP1 gene-transfected autologous mesenchymal cells derived from bone marrow. Rheumatology (Oxford) 43: 980-985.

Kim D, Cho SW, Her SJ, Yang JY, Kim SW, Kim SY, Shin CS (2006) Retrovirus-mediated gene transfer of RANK-Fc prevents bone loss in ovariectomized mice. Stem Cells 24: 1798-1805.

Kumar S, Mahendra G, Nagy TR, Ponnazhagan S (2004) Osteogenic differentiation of recombinant adenoassociated virus 2-transduced murine mesenchymal stem cells and development of an immunocompetent mouse model for ex vivo osteoporosis gene therapy. Hum Gene Ther 15: 1197-1206.

Kumar S, Mahendra G, Ponnazhagan S (2005) Determination of osteoprogenitor-specific promoter activity in mouse mesenchymal stem cells by recombinant adeno-associated virus transduction. Biochim Biophys Acta 1731: 95-103.

McMahon JM, Conroy S, Lyons M, Greiser U, O'shea C, Strappe P, Howard L, Murphy M, Barry F, O'Brien T (2006) Gene transfer into rat mesenchymal stem cells: a comparative study of viral and nonviral vectors. Stem Cells Dev 15: 87-96.

Murphy JM, Dixon K, Beck S, Fabian D, Feldman A, Barry F (2002) Reduced chondrogenic and adipogenic activity of mesenchymal stem cells from patients with advanced osteoarthritis. Arthritis Rheum 46: 704-713.

Murphy JM, Fink DJ, Hunziker EB, Barry FP (2003) Stem cell therapy in a caprine model of osteoarthritis. Arthritis Rheum 48: 3464-3474.

Muraglia A, Corsi A, Riminucci M, Mastrogiacomo M, Cancedda R, Bianco P, Quarto R (2003) Formation of a chondro-osseous rudiment in micromass cultures of human bone-marrow stromal cells. J Cell Sci 116: 29492955.

Pittenger MF, Mackay AM, Beck SC, Jaiswal RK, Douglas R, Mosca JD, Moorman MA, Simonetti DW, Craig S, Marshak DR (1999) Multilineage potential of adult human mesenchymal stem cells. Science 284: 143147.

Orlic D, Kajstura J, Chimenti S, Jakoniuk I, Anderson SM, Li B, Pickel J, McKay R, Nadal-Ginard B, Bodine DM, Leri A, Anversa P (2001) Bone marrow cells regenerate infarcted myocardium. Nature 410: 701-705.

Ponnazhagan S, Mukherjee P, Wang XS, Qing K, Kube DM, Mah C, Kurpad C, Yoder MC, Srour EF, Srivastava 
A. (1997) Adeno-associated virus type 2-mediated transduction in primary human bone marrow-derived CD34+ hematopoietic progenitor cells: donor variation and correlation of transgene expression with cellular differentiation. J Virol 71: 8262-8267.

Reiser J, Zhang XY, Hemenway CS, Mondal D, Pradhan L, La Russa VF (2005) Potential of mesenchymal stem cells in gene therapy approaches for inherited and acquired diseases. Expert Opin Biol Ther 5: 1571-1584.

Saretzki G, Armstrong L, Leake A, Lako M, von Zglinicki T (2004) Stress defense in murine embryonic stem cells is superior to that of various differentiated murine cells. Stem Cells 22: 962-971.

Stagg J, Lejeune L, Paquin A, Galipeau J (2004) Marrow stromal cells for interleukin-2 delivery in cancer immunotherapy. Hum Gene Ther 15: 597-608.

Summerford C, Samulski RJ (1998) Membraneassociated heparan sulfate proteoglycan is a receptor for adeno-associated virus type 2 virions. J Virol 72: 14381445.

Tuli R, Tuli S, Nandi S, Wang ML, Alexander PG, Haleem-Smith H, Hozack WJ, Manner PA, Danielson KG, Tuan RS (2003) Characterization of multipotential mesenchymal progenitor cells derived from human trabecular bone. Stem Cells 21: 681-693.

Wakitani S, Saito T, Caplan AI (1995) Myogenic cells derived from rat bone marrow mesenchymal stem cells exposed to 5-azacytidine. Muscle Nerve 18: 1417-1426.

Wakitani S, Imoto K, Yamamoto T, Saito M, Murata N, Yoneda M (2002) Human autologous culture expanded bone marrow mesenchymal cell transplantation for repair of cartilage defects in osteoarthritic knees. Osteoarthritis Cartilage 10: 199-206.

Wang L, Li Y, Chen X, Chen J, Gautam SC, Xu Y, Chopp M (2002) MCP-1, MIP-1, IL-8 and ischemic cerebral tissue enhance human bone marrow stromal cell migration in interface culture. Hematology 7: 113-117.

Wollert KC, Meyer GP, Lotz J, Ringes-Lichtenberg S, Lippolt P, Breidenbach C, Fichtner S, Korte T, Hornig B, Messinger D, Arseniev L, Hertenstein B, Ganser A, Drexler $\mathrm{H}$ (2004) Intracoronary autologous bone-marrow cell transfer after myocardial infarction: the BOOST randomised controlled clinical trial. Lancet 364: 141-148.

\section{Discussion with Reviewers}

B. Johnstone: Since the cells are not selected by means other than plate adherence and passage, it is possible that there is still heterogeneity in the transduced cultures. With evidence of heterogeneity of transduction, could subpopulations of cells be distinguished and differentiation capacity compared?

Authors: Certainly these cultures may be heterogeneous and plate adherence is a crude method of selection. Separation of subpopulations based on transduction efficiency is a useful approach in trying to understand this heterogeneity and could be approached by high speed cell sorting, for instance. It is interesting to contemplate whether there may be a link between transduction capacity and differentiation. The experimental approach is straightforward and it may give rise to useful new information about the microheterogeneity of these cells.

B. Johnstone: Are the authors considering methods to improve transduction and increase the low level of AAV transgene expression in MSCs? For example, other AAV serotypes may provide better transduction levels in MSCs. Authors: There are other approaches which will lead to a higher efficiency of transduction and these are worth exploring in detail. Recently we published a study (McMahon et al., 2006; text reference) using rat MSCs and a range of vectors was tested on the same stem cell preparation. Adenovirus, AAV serotypes 1, 2, 4, 5, and 6, lentivirus, and nonviral vectors were compared. Lentivirus proved to be most effective with transduction efficiencies of up to $95 \%$, concurrent with low levels of cell toxicity. Adenovirus also proved effective, but a significant increase in cell death was seen with increasing viral titer. Interestingly, rat MSCs remained refractory to transduction by all AAV serotypes, in contrast to rabbit MSCs tested at the same time. Lipofection of plasmid DNA gave moderate transfection levels but was also accompanied by cell death. Electroporative gene transfer proved ineffective at the parameters tested and resulted in high cell death. High and moderate levels of cell transduction using lentivirus vectors did not affect the ability of the cells to differentiate down the adipogenic pathway.

M. Stoddart: All the data showing highest efficiency $(65 \%)$ and highest MFI was carried out using 10,000 MOI. A successful therapy is likely to require high transduction efficiency, high expression efficiency or both. Why did the authors choose a 100 fold lower MOI (100 MOI) for the differentiation experiments?

Authors: This is a valid point and in an ideal context the differentiation potential would be monitored at the MOI that gives the highest efficiency of transduction. The point of the experiment was to determine that the phenotype of the cells was not altered by transduction and this has been demonstrated as reported in the manuscript. If AAVtransduced MSCs were to be used clinically it would be necessary to explore the effect of differentiation in more detail. 